\title{
Responses of Small Intrapulmonary Arteries to Vasoactive Compounds in the Fetal and Neonatal Lamb: Norepinephrine, Epinephrine, Serotonin, and Potassium Chloride
}

\author{
JULIE A. DUNN, VICHIEN LORCH, AND SACHCHIDA N. SINHA \\ Department of Pediatrics, University of Tennessee Memorial Research Center and Hospital, \\ Knoxville, Tennessee 37920
}

\begin{abstract}
Despite considerable study, the mechanisms responsible for the transition of the pulmonary circulation from the fetal to newborn life remain obscure. We compared the responses of third and fourth generation pulmonary arteries to norepinephrine, epinephrine, serotonin, and $\mathrm{KCl}$ from lambs $7 \mathrm{~d}$ preterm and 1, 7, and $21 \mathrm{~d}$ of age to assess differences between age and third and fourth generations of the pulmonary arterial tree during the transitional period. Preterm vessels were significantly smaller in internal diameter than all other aged vessels for both generations. Fourth generation vessel response to $\mathrm{KCI}$ increased with age $\left(94 \pm 15 \mathrm{mg} / \mathrm{mm}^{2}\right.$, preterm; $259 \pm 31$ $\mathrm{mg} / \mathrm{mm}^{2}, 21 \mathrm{~d}$ ). Third generation vessel response to $\mathrm{KCl}$ did not change with age $\left(135 \pm 15 \mathrm{mg} / \mathrm{mm}^{2}\right.$, preterm; 158 $\left.\pm 18 \mathrm{mg} / \mathrm{mm}^{2}, 21 \mathrm{~d}\right)$. There were no differences in maximum response to norepinephrine and epinephrine between ages; however, third generation vessel response to these compounds was significantly greater $(30-60 \%$ of maximum $\mathrm{KCl}$ response) than fourth generation vessel response (0$10 \%$ ). Third and fourth generation vessels had the same maximum response to serotonin regardless of age or generation. Third generation vessels were significantly reduced in sensitivity (log molar concentration which produced $50 \%$ of the maximum response- $-\mathbf{E C}_{50}$ ) to norepinephrine at $\mathbf{d} \mathbf{1}$ $(5.89 \pm 0.12 \log$ molar) and $7(5.90 \pm 0.21)$ compared to preterm $(6.48 \pm 0.10)$ and $21 \mathrm{~d}$ of age $(6.50 \pm .03)$. Both third and fourth generation vessels were less sensitive to serotonin at $\mathrm{d} 1(\mathbf{5 . 0 4} \pm 0.17$, third; $5.61 \pm 0.10$, fourth) compared to $\mathrm{d} 7(5.77 \pm 0.13$, third; $6.36 \pm 0.12$, fourth) and $21 \mathrm{~d}(5.82 \pm 0.24$, third; $6.50 \pm 0.15$, fourth). A similar nonsignificant trend occurred in third generation vessels to epinephrine at $\mathrm{d} 1$ and 7 compared to vessels at preterm and $21 \mathrm{~d}$ of age. Greater than $75 \%$ of fourth generation vessels did not respond to norepinephrine and epinephrine. The small intrapulmonary arteries of the neonate are undergoing dynamic changes in physiologic response which are dependent upon age and generation. (Pediatr Res $25: 360-363,1989$ )
\end{abstract}

\section{Abbreviations}

NE, norepinephrine

EPI, epinephrine

5HT, 5-hydroxytryptamine, serotonin

Received April 5, 1988; accepted November 16, 1988

Correspondence Julie A. Dunn, c/o Vichien Lorch, Department of Pediatrics D113, University of Tennessee Memorial Research Center and Hospital, 1924 Alcoa Highway, Knoxville, TN 37920.
At birth, the neonatal lung is still undergoing maturation and development: multiplication of intraalveolar vessels, remodeling of vessels under $250 \mu \mathrm{m}$, and extension of smooth muscle into the alveolar region occur (1-8). Physiologically, the lungs adapt to extrauterine life with a progressive decrease in pulmonary vascular resistance and increase in blood flow to perform the vital function of gas exchange. However, despite considerable study, the mechanisms involved in the neonatal transitional circulation remain obscure.

A wealth of information exists regarding the contractility and reactivity of large diameter vessels $(>1 \mathrm{~mm})$ in the neonatal lung (9-11). However, arteries with a diameter greater than $500 \mu \mathrm{m}$ are unimportant in controlling resistance (12). Furthermore, because of tremendous regional variation in both structure and function throughout the vasculature, extrapolation of data from larger vessels to those less than $500 \mu \mathrm{m}$ is inappropriate $(11,13-$ 18). An assessment of blood vessel response at levels potentially important in controlling pulmonary vascular resistance and flow may further clarify the mechanisms of the transitional circulation.

In this study we examined the reactivity and contractility of third generation pulmonary vessels $(530-1000 \mu \mathrm{m}$, internal diameter) and fourth generation pulmonary vessels $(175-330 \mu \mathrm{m}$, internal diameter) to the vasoactive compounds NE, EPI, $5 \mathrm{HT}$, and $\mathrm{KCl}$ in the lamb at $1 \mathrm{wk}$ preterm and 1,7 , and $21 \mathrm{~d}$ of age, over a period of adaptation to extrauterine life.

\section{MATERIALS AND METHODS}

Fetal and neonatal purebred lambs were used. Preterm lambs of approximately 136-140 d of gestation were delivered by cesarean section and a saline-filled bag was placed over the nose to prevent breathing. Lambs of 1,7 , and $21 \mathrm{~d}$ of age were delivered by natural birth without intervention. For all ages, a euthanizing intracardiac dose $(45 \mathrm{mg} / \mathrm{kg})$ of sodium pentobarbital (Elkins-Sinn, Inc.) was injected. In preterm animals, the cord was then clamped and cut. The lungs and heart were rapidly removed en bloc via a median sternotomy. The ductus arteriosus was not manipulated in any of the animals. The pulmonary vascular bed was injected with cold $\left(4^{\circ} \mathrm{C}\right)$, oxygenated $\left(95 \% \mathrm{O}_{2^{-}}\right.$ $5 \% \mathrm{CO}_{2}$ ) Krebs bicarbonate solution (composition in $\mathrm{mM}: \mathrm{NaCl}$ $118.3, \mathrm{KCl} 4.7, \mathrm{KH}_{2} \mathrm{PO}_{4} 1.2, \mathrm{MgSO}_{4} 1.2, \mathrm{NaHCO}_{3} 25.0, \mathrm{CaCl}_{2}$ 2.5 , and glucose 11.1) through an incision in the right ventricle. The main pulmonary artery was dissected free and cut longitudinally down the right and left branches to the base of both lungs and down third generation arteries. Blocks of lung tissue containing third and fourth generation arteries were excised, placed in cold Krebs solution, and segments were dissected free and cleaned of surrounding parenchyma. Vessel segments were 
threaded onto two $40-\mu \mathrm{m}$ stainless steel wires (California Fine Wire Co.) and secured to mounting supports. The mounting supports were attached on one side to a displacement micrometer (Starret) and on the other side to a force transducer (KistlerMorse DSC-6BE4-1 10, Kistler Instrument Corp., Amherst, NY) to record isometric tension. Responses were amplified (Beckman RB Dynograph, Beckman Instruments Inc., Fullerton, CA) and recorded on a 2-channel rectilinear chart recorder (Kipp \& Zonen Model BD 41, Bohemia, NY).

The vessels were equilibrated for $90 \mathrm{~min}$ while temperature was brought up to $37^{\circ} \mathrm{C}$. At the end of the equilibration period, a length-tension curve was performed by stretching in increments and stimulating the vessels with isoosmotic $125 \mathrm{mM} \mathrm{KCl}$ solution until an optimal contractile response was obtained. Vessel diameters were measured via the displacement micrometers and circumferences were calculated (19).

Standard cumulative half-log dose response curves were generated to NE (Winthrop-Breon) EPI (Parke, Davis \& Co., Detroit, MI) and 5HT (Sigma Chemical Co., St. Louis, MO) by the method of Van Rossum (20). Fresh stock solutions of all drugs were made and used within $8 \mathrm{~h}$.

Responses to $\mathrm{KCl}$ were expressed as $\mathrm{mg} / \mathrm{mm}^{2}$ (vessel circumference $\times$ length). As we did not know whether blood vessels of different sizes had the same amount and arrangement of smooth muscle, the constrictor responses were normalized in terms of the maximum response to $\mathrm{KCl}(16)$ where:

\section{Response $(\%)=\mathrm{mg} / \mathrm{mm}^{2}$ constrictor $/ \mathrm{mg} / \mathrm{mm}^{2} \mathrm{KCl} \times 100$}

The sensitivity to each compound was assessed by determining the concentration which produced $50 \%$ of the maximal response $\left(\mathrm{EC}_{50}\right)$ extrapolated from a plot of $\log$ concentration versus percentage of the maximal response. The $\mathrm{EC}_{50}$ responses are expressed as a negative logarithm $\left(-\log\right.$ molar $\left.\mathrm{EC}_{50}\right)$. Two-way ANOVA and Tukey's HSD test were used to compare internal diameters and response to $\mathrm{KCl}$. Repeated measures (dose) 2-way ANOVA and Tukey's HSD test were used to compare differences of main treatment effects.

\section{RESULTS}

Internal diameter. Table 1 shows the internal diameters in micrometers of third and fourth generation vessels as a function of age. Third generation vessels were significantly larger than fourth generation vessels in internal diameter $(p<0.0001)$. Preterm vessels were significantly smaller than vessels at all other ages $(p<0.005)$. In addition, a significant statistical interaction occurred between age and generation $(p<0.05)$.

Response to $\mathrm{KCl}$. The response of third and fourth generation vessels to $\mathrm{KCl}$ are shown as a function of age (Table 2). Day 21 response was significantly greater than preterm vessel response $(p<0.005)$. Third and fourth generation vessels were similar in their response to $\mathrm{KCl}$. A statistically significant interaction was determined between age and generation $(p<0.01)$.

Maximum response to vasoactive compounds. Figures 1 through 3 show the responses of third and fourth generation blood vessels expressed as a percentage of the $\mathrm{KCl}$ response. Third generation vessels had a significantly greater maximal response to NE $(p<0.0001)$ and $\mathrm{EPI}(p<0.0005)$ than fourth generation vessels at all ages (Fig. $1 A$ and $B$ and Fig. $2 A$ and $B)$. No differences were detected between ages. Third generation vessels were not different between ages or generation to $5 \mathrm{HT}$ (Fig. $3 A$ and $B$ ).

Sensitivity to vasoactive compounds. The $-\log$ molar $\mathrm{EC}_{50}$ values to EPI, NE, and 5HT are shown in Table 3 . Because of lack of responsiveness $(>75 \%)$ to $\mathrm{NE}$ and EPI in fourth generation vessels, $\mathrm{EC}_{50}$ values were not calculated. Third generation vessels were significantly less sensitive to NE at $\mathrm{d} 1$ and 7 compared to preterm and $\mathrm{d} 21$ vessels $(p<0.005)$. This same trend, although not significant, also occurred at $\mathrm{d} 1$ and 7 to EPI. Both third and fourth generation vessels were significantly
Table 1. Internal diameters (in $\mu m$ ) (mean \pm SEM) of third and fourth generation blood vessels

\begin{tabular}{ccccc}
\hline & \multicolumn{4}{c}{ Age } \\
\cline { 2 - 5 } Generation & $\begin{array}{c}\text { Preterm* } \\
(n=5)\end{array}$ & $\begin{array}{c}\mathrm{D} 1 \\
(n=12)\end{array}$ & $\begin{array}{c}\mathrm{D} 7 \\
(n=11)\end{array}$ & $\begin{array}{c}\mathrm{D} 21 \\
(n=11)\end{array}$ \\
\hline Third $\dagger$ & $530 \pm 40$ & $880 \pm 70$ & $965 \pm 110$ & $1000 \pm 60$ \\
Fourth & $175 \pm 15$ & $330 \pm 40$ & $275 \pm 25$ & $245 \pm 20$ \\
\hline
\end{tabular}

* Preterm vessels significantly smaller than all other ages $(p<0.01)$.

$\dagger$ Third generation vessels significantly larger than fourth generation vessels at all ages $(p<0.001)$.

Table 2. Response (in $\mathrm{mg} / \mathrm{mm}^{2}$ ) (mean $\pm S E M$ ) of third and fourth generation vessels to $125 \mathrm{mM} \mathrm{KCl}$

\begin{tabular}{crccc}
\hline & \multicolumn{4}{c}{ Age } \\
\cline { 2 - 5 } Generation & $\begin{array}{c}\text { Preterm* } \\
(n=5)\end{array}$ & $\begin{array}{c}\mathrm{D} 1 \\
(n=12)\end{array}$ & $\begin{array}{c}\mathrm{D} 7 \\
(n=11)\end{array}$ & $\begin{array}{c}\mathrm{D} 21 \\
(n=11)\end{array}$ \\
\hline Third & $136 \pm 15$ & $189 \pm 32$ & $103 \pm 12$ & $158 \pm 18$ \\
Fourth & $94 \pm 14$ & $165 \pm 22$ & $183 \pm 16$ & $259 \pm 31$ \\
\hline
\end{tabular}

* Preterm vessels significantly different from $21 \mathrm{~d}$ vessels, fourth gencration $(p<0.005)$.

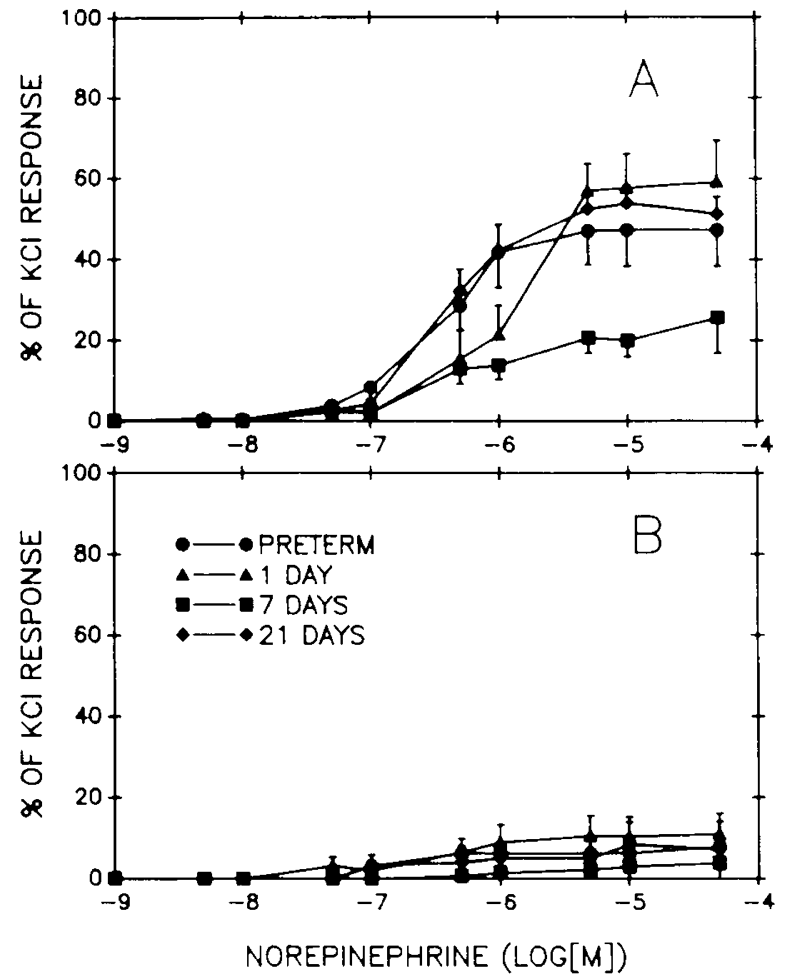

Fig. 1. Responses of third $(A)$ and fourth $(B)$ generation vessels at preterm and $\mathrm{d} 1,7$, and 21 to NE normalized as a function of the $\mathrm{KCl}$ response.

less sensitive to 5HT at $\mathrm{d} 1$ compared to $\mathrm{d} 7$ and $21(p<0.0001)$. In addition, fourth generation vessels were significantly more sensitive to 5 HT than third generation vessels $(p<0.0001)$. Preterm vessel response to $5 \mathrm{HT}$ was not performed.

\section{DISCUSSION}

This work has demonstrated that third and fourth generation pulmonary arteries of the neonatal lamb differ in their responsiveness to the vasoaactive compounds $\mathrm{KCl}, \mathrm{NE}$, EPI, and $5 \mathrm{HT}$ in vitro. These differences suggest that for a complete understanding of the transitional circulation it is necessary to assess re- 

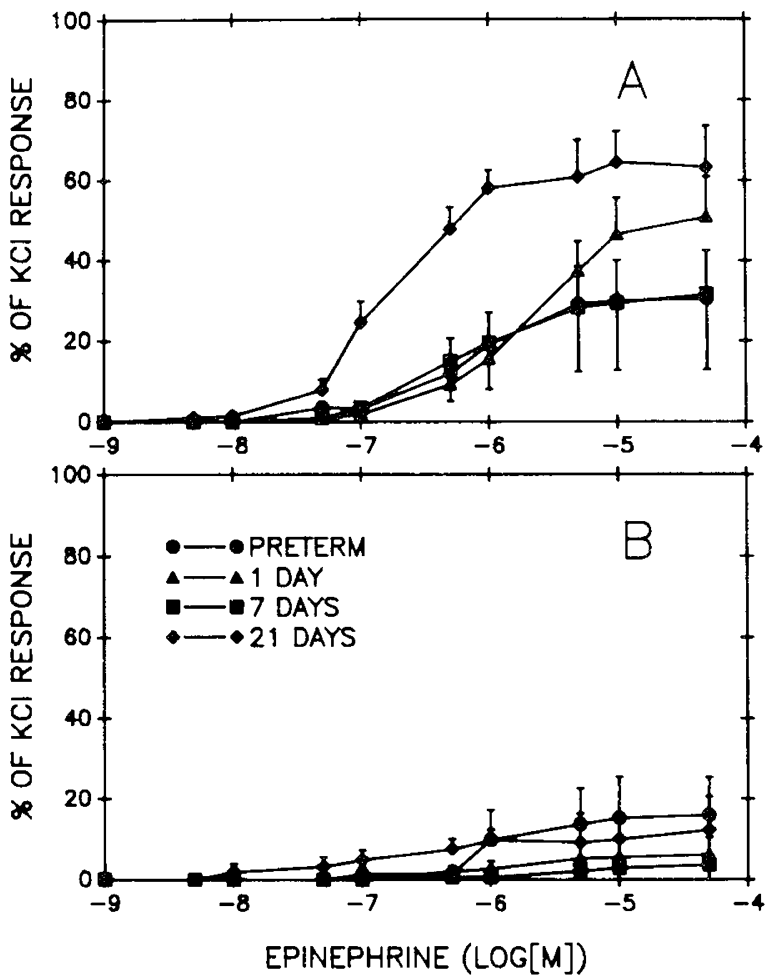

Fig. 2. Responses of third $(A)$ and fourth $(B)$ generation vessels at preterm and $\mathrm{d} 1,7$, and 21 to EPI normalized as a function of the $\mathrm{KCl}$ response.
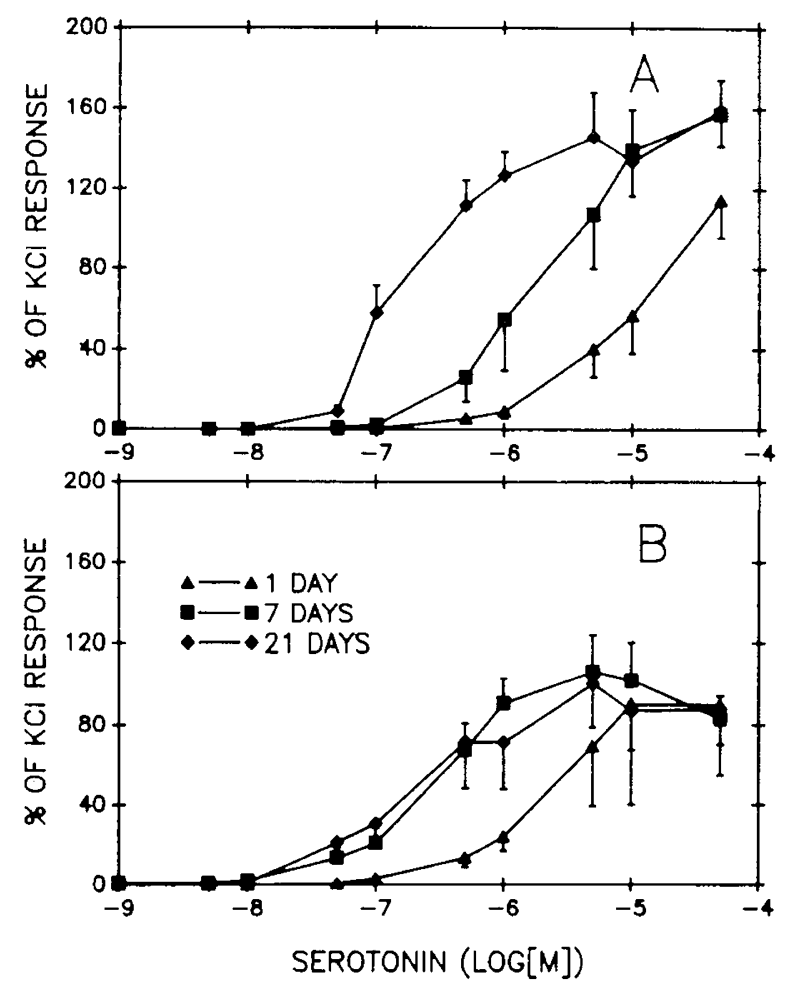

Fig. 3. Responses of third $(A)$ and fourth $(B)$ generation vessels at $\mathrm{d}$ 1,7 , and 21 to serotonin normalized as a function of the $\mathrm{KCl}$ response.

sponses at vessels more important in controlling pulmonary resistance and flow.

The significantly smaller internal diameters of preterm vessels compared to all other ages is consistent with the drop in pulmonary vascular resistance at birth. We do not feel that growth
Table 3. - Log molar $E C_{50}$ values (mean $\pm S E M$ ) for third and fourth generation vessels to NE, EPI, and $5 H T$

\begin{tabular}{lllccc}
\hline & & \multicolumn{4}{c}{ Age } \\
\cline { 3 - 6 } Drug & Generation & $\begin{array}{c}\text { Preterm } \\
(n=4)\end{array}$ & $\begin{array}{c}\text { D 1 } \\
(n=8)\end{array}$ & $\begin{array}{c}\mathrm{D} 7 \\
(n=6)\end{array}$ & $\begin{array}{c}\mathrm{D} 21 \\
(n=6)\end{array}$ \\
\hline \multirow{2}{*}{$\mathrm{NE}$} & Third & $6.48 \pm .10$ & $5.89 \pm .12^{*}$ & $5.90 \pm .21^{*}$ & $6.50 \pm .03$ \\
& Fourth & & & & \\
\multirow{2}{*}{ EPI } & Third & $6.20 \pm .03$ & $5.77 \pm .11$ & $5.64 \pm .24$ & $6.20 \pm .25$ \\
& Fourth & & & & \\
\multirow{2}{*}{$5 \mathrm{HT}$} & Third & & $5.04 \pm .17 \dagger$ & $5.77 \pm .13$ & $5.82 \pm .24$ \\
& Fourth $\neq$ & & $5.61 \pm .10$ & $6.36 \pm .12$ & $6.50 \pm .15$ \\
\hline
\end{tabular}

${ }^{*} \mathrm{D} 1$ and 7 vessels significantly less sensitive to NE than preterm and d 21 vessels $(p<0.005)$.

$\dagger \mathrm{D} 1$ vessels significantly less sensitive to $5 \mathrm{HT}$ than $\mathrm{d} 7$ and 21 aged vessels $(p<0.0001)$.

$\ddagger$ Fourth generation vessels significantly more sensitive to $5 \mathrm{HT}$ than third generation vessels at all ages $(p<0.0001)$.

alone can account for these diameter differences. Pulmonary vascular remodeling occurs throughout the the postnatal ages tested, yet d 1, 7, and 21 vessels were not different in internal diameter. Both lung expansion and alveolar oxygenation play a role in decreasing the pulmonary vascular resistance at birth; however, the relative contribution of these factors is an area of some debate (21-24). In this study, fetal and neonatal vessels were removed and placed in Krebs solution perfused with 95\% oxygen. Also, the fetal lung never underwent lung expansion. Thus, while oxygen may be an important mediator of pulmonary vasodilation at birth, it may not be an initiating or sustaining factor. In addition, oxygen may require an intact pulmonary bed to mediate the vasodilatory process at birth.

A statistically significant interaction was encountered for internal diameter between age and generation. A comparison of third and fourth generation vessel internal diameter shows that these vessels do not change in a parallel fashion with age. The third generation vessel internal diameter progressively increases with age. The fourth generation vessel internal diameter increases at $1 \mathrm{~d}$ of age and then progressively decreases at $\mathrm{d} 7$ and 21 . This may reflect the dramatic remodeling of the small vessels and extension of vascular smooth muscle $(1,8)$.

Although the muscular wall thickness was not obtained in this study, the response to $\mathrm{KCl}$, which is mediated through its effect on the membrane potential (25) and is therefore receptor independent, indicates the integrity and mass of smooth muscle present. Third generation arteries did not show any changes in $\mathrm{KCl}$ response over time, suggesting that the smooth muscle at this generation did not undergo detectable functional alteration throughout the time period tested. However, fourth generation vessel response to $\mathrm{KCl}$ continued to increase over the time period tested, indicating smooth muscle extension or maturation at this generation. Certainly the muscular coat at this generation is not thinning and therefore would not account for the diameter increases that occurred at birth.

Third generation maximal response was similar between ages to NE and EPI and between ages and generation to 5HT. Thus, there are no changes in receptor quantity in these vessels (10, 20 ). However, there is a relative paucity of receptors to EPI and $\mathrm{NE}$ in fourth generation vessels compared to third generation vessels as indicated by the significantly smaller maximal response to these compounds. Decreases in adrenergic activity with decreases in vessel diameter have also been reported in the rabbit lung (26). The significance of this finding was not discussed, but may reflect the relative lack of vasomotor tone in the adult lung (13).

Unlike maximal contractile response, the sensitivity of vessels to EPI and NE decreased at 1 and $7 \mathrm{~d}$ in third generation vessels. Also, both third and fourth generation vessels were least sensitive to $5 \mathrm{HT}$ at $1 \mathrm{~d}$ of age. The decreased sensitivity at these ages may 
be due to the degree of neuronal and extraneuronal uptake (14). Furthermore, this decrease in sensitivity may be an important mechanism in the neonate to adjust to the stress of birth. During the birth process, high levels of catecholamines are released into the circulation $(27,28)$. The pulmonary vascular bed may exhibit selective desensitization of the third generation vessels and a paucity of adrenergic receptors of the fourth generation vessels. Thus, the dramatic drop in pulmonary vascular resistance necessary at birth is maintained, despite the presence of high circulating vasoconstrictor agents.

A high concentration of oxygen (95\%), a potent pulmonary vasodilator, was perfused throughout our studies. Oxygen may selectivity exert effects that either decrease or eliminate the responses to NE and EPI. This possibility and the possibility of increased adrenergic uptake require further study.

Serotonin produced a marked vasoconstrictor response that exceeded the maximal response to $\mathrm{KCl}$ in both third and fourth generation vessels. Its ability to produce a marked vasoconstrictor response in the absence of effects to EPI and NE of the fourth generation vessels, indicates that the serotonin response was not mediated by $\alpha$ receptors. Work using specific serotonergic agonists and antagonists would be helpful in clarifying this response.

In conclusion, the neonatal pulmonary vascular bed is undergoing dynamic changes characterized by a developing vascular smooth muscle effector system of the fourth generation vessels and by changes in agonist affinity of both third and fourth generation vessels. These changes are dependent upon age and generation. This study verifies that third and fourth generation vessels are quite different in their patterns of responsiveness. Thus, responsiveness of large arteries does not reflect the reactivity of arteries and arterioles important in controlling pulmonary vascular hemodynamics of the fetus and newborn.

$A C K N O W L E D G M E N T S$. The authors would like to thank Dr. Mulvany and John Pederson at the Institut of Biophysiks in Aarhus, Denmark, for the blueprints of the myograph. We would also like to thank Shirley and George Debusk.

\section{REFERENCES}

1. Hislop A, Reid L 1973 Pulmonary arterial development during childhood: branching pattern and structure. Thorax 28:129-135

2. Inselman I..S, Mellins RB 1981 Growth and development of the lung. J Pediat $98: 1-15$

3. Levin DL, Rudolph AM. Heymann MA, Phibbs RH 1976 Morphological development of the pulmonary vascular bed in fetal limbs. Circulation 53:144-151

4. Meyrick B, Reid L 1982 Pulmonary arterial growth and alveolar development in normal postnatal rat lung. Am Rev Respir Dis 125:468-473

5. Reid L 1977 The lung: its growth and remodeling in health and disease. AJR
129:777-788

6. Rendas A, Branthwaite M, Reid L 1978 Growth of pulmonary circulation in normal pig: structural analysis and cardiopulmonary function. J Appl Physiol 45:806-817

7. Hislop A, Reid L 1972 Intrapulmonary arterial development during fetal life: branching pattern and structure. J Anat 113:35-48

8. Meyrick B, Reid L 1973 Pulmonary arterial and alveolar development in normal postnatal rat lung. Am Rev Respir Dis 125:468-473

9. Green RS, Leffler CW 1984 A comparison of the sensitivities of neonatal ovine pulmonary and femoral arteries to 1-norepinephrine stimulation. Pediatr Res 18:244-247

10. Newman JH, Souhrada JF, Reeves JT, Arroyave CM, Grover RF 1979 Postnatal changes in response of canine neonatal pulmonary arteries to histamine. Am J Physiol 237:H76-H82

11. Su C, Bevan JA, Assali NS, Brinkman CR 1977 Regional variation of lamb blood vessel responsiveness to vasoactive agents during fetal development. Circ Res 41:844-848

12. Andersson KE, Hogestatt ED, Skarby T, Uski TK 1985 Some aspects of the pharmacology of resistance vessels. Prog Appl Microcirc 8:19-31

13. Bevan JA, Bevan RD 1984 Patterns of a-adrenergic regulation of the vasculature. Blood Vessels 21:110-116

14. Buckner CK, Cueva S, Abdalla S, Will JA 1982 Studies on segmental differences in sensitivity to adrenergic agonists in pulmonary arteries isolated from the guinea pig. Eur J Pharmacol 82:137-146

15. Holl JE, Kolbeck RC, Speir WA 1980 Pulmonary vascular responsiveness to histamine: Exquisite sensitivity of small intrapulmonary arteries. Am Rev Respir Dis 122:909-913

16. Kong SK, Stephens NL 1984 Pharmacological properties of canine intrapulmonary blood vessels. Can J Physiol Pharmacol 62:1198-1202

17. Muller-Schweinitzer E, Weidmann F 1977 Regional differences in the responsiveness of isolated arteries from cattle, dog and man. Agents Actions 7:383387

18. Somlyo AV, Sandberg RL, Somlyo AP 1965 Pharmacologically heterogeneous smooth muscle cell distribution in blood vessels. J Pharmacol Exp Ther 149:106-112

19. Mulvany MJ, Halpern W 1976 Mechanical properties of vascular smooth muscle cells in situ. Nature 260:617-619

20. Van Rossum JM 1963 Cumulative dose-response curves II: techniques for the making of dose-response curves in isolated organs and the evaluation of drug parameters. Arch Int Pharmacodyn Ther 143:299-330

21. Assali NS, Kirschbaum TH, Dilts PV 1968 Effects of hyperbaric oxygen on uteroplacental and fetal circulation. Circ Res 22:573-588

22. Cassin S, Dawes GS, Mott JC, Ross BB, Strang LB 1964 The vascular resistance of the foetal and newly ventilated lung of the lamb. J Physiol (Lond) 171:6179

23. Rudolph AM, Teitel DF, Iwamoto HS, Gleason CA 1986 Ventilation is more important than oxygenation in reducing pulmonary vascular resistance at birth. Pediatr Res 20 (suppl):439(abstr)

24. Rudolph AM 1977 Fetal and neonatal pulmonary circulation. Am Rev Respir Dis 115:11-18

25. Burnstock G, Holman ME, Prosser CL 1963 Electrophysiology of smooth muscle. Physiol Rev 43:482-527

26. Su C, Bevan RD, Duckles SP, Bevan JA 1978 Functional studies of small pulmonary arteries. Microvasc Res 15:37-44

27. Agata Y Padbury JF, Ludlow J, Polk D Humme J 1986 The effect of chemical sympathectomy on the catecholamine (CAT) surge at birth. Pediatr Res 20 (suppl): 184(abstr)

28. Padbury JF, Agata Y, Ludlow JK, Humme JA 1987 The effects of fetal adrenalectomy on catecholamine (CA) release and circulatory adjustments at birth. Pediatr Res 21 (suppl):386(abstr) 